\section{Research Article}

(C) 2020 Serpa et.al.. This is an open access article licensed under the Creative Commons Attribution-NonCommercial 4.o International License (https://creativecommons.org/licenses/by-nc/4.o/)

\title{
Challenges for the Academic Editor in the Scientific Publication
}

\author{
Sandro Serpa \\ University of The Azores, \\ Faculty of Social and Human Sciences, Department of Sociology, \\ Interdisciplinary Centre of Social Sciences - CICS.UAc/CICS.NOVA.Uac; \\ Interdisciplinary Centre for Childhood and \\ Adolescence - NICA - UAc, The Azores, Portugal \\ ${ }^{*}$ Corresponding Author \\ Maria José Sá \\ CIPES-Centre for Research in \\ Higher Education Policies, Matosinhos, Portugal \\ Ana Isabel Santos \\ University of The Azores, Faculty of Social Sciences and Humanities; \\ Interdisciplinary Centre for Childhood and \\ Adolescence-NICA-Uac, The Azores, Portugal \\ Carlos Miguel Ferreira \\ Interdisciplinary Centre of Social Sciences - CICS.NOVA, Portugal \\ ISCTE - University Institute of Lisbon, Portugal
}

\section{Doi: 10.36941/ajis-2020-0037}

\section{Abstract}

The academic editor has been, and still is, the gatekeeper of peer-reviewed scientific publications, by being whom, ultimately, defines whether or not a manuscript can be published. At a time of profound transformation in the context of scientific publication (digital publishing, open access, preprint, open peer review,...) and the expectations, inside and outside academia, towards academic publication, this perspective paper aims to add to the discussion of the (re)formulation of the academic editor's role, considering that he or she, in this panoply of changes, continues, and will continue to be, the ultimate guardian of the scientific quality of what is published.

Keywords: academic editor, scholarly publication, scientific publication, scholarly communication.

The editor of an academic journal, despite doing it pro bono, represents (or at least should represent) one of the most important positions for influencing one's own community, particularly when it comes to the most contemporary research topics. (Herteliu, Ausloos, Ileanu, Rotundo, \& Andrei, 2017, p. 1) 


\section{Introduction}

We live in a moment of profound transformation of the context (digital publishing, open access, preprint, open peer review,...) and expectations (inside and outside academia) towards the academic publication (Ghanbari Baghestan et al., 2019). Baffy et al. (2020) maintain that "Scholarly communication is being transformed by complex digital tools such as online access, social media, and big data management" (p. 27). This is a context in which "The current discourse on research productivity (how much peer-reviewed academic output is published by faculty) is dominated by quantitative research on individual and institutional traits; implicit assumptions are that academic writing is a predominately cognitive activity, and that lack of productivity represents some kind of deficiency" (Nygaard, 2017, p. 519).

The academic editor has been, and still is, the gatekeeper of peer-reviewed scientific publications, by being who, ultimately, defines whether or not a manuscript can be published, functioning as a direct agent for legitimising the scientific publication (Primack et al., 2019; Herteliu et al., 2017; Watson \& Xue, 2019). This paper aims to add to the discussion of the (re)formulation of the academic editor's role.

\section{The academic editor and the scientific publication}

The pressure to publish - the already famous publish or perish (Chiriboga, 2019) - is felt with enormous urgency in the academic world, with the profound implications of publishing in the image of both academics and higher education institutions, in a world where global competition is already a reality (Omer, 2015). According to Abbott (2019), "This new pressure arises from essential changes at the heart of academic life" (p. 10).

The context of scientific publication - which is critical for the dissemination of scientific knowledge (Wong, 2019; Baffy et al., 2020) -, while being an industry with an annual with a turnover of millions of dollars and euros in one year (Pagliaro, 2019; Banks et al., 2018; Kortabarria, 2019), is undergoing a deep change (Trapp, 2019) with the unstoppable Open Access (Ghanbari Baghestan et al., 2019; Tenopir et al., 2016; Miguel, Tannuri de Oliveira, \& Cabrini Grácio, 2016; Baffy et al., 2020; Kortabarria, 2019). Six dimensions may be highlighted on this important phenomenon - as an illustration, and without being exhaustive, but that can be developed by consulting the literature on this topic -, which academic editors will have to address, as depicted in Table 1.

Table 1. Challenges for academic publishers

\begin{tabular}{l|l} 
Open Access & Free access to scientific publications \\
$\begin{array}{l}\text { Indexing } \\
\text { Metrics }\end{array}$ & The indexation of journals to the most reputable bases \\
The number of citations of the articles
\end{tabular}

Source: Own production, based on Tennant et al., 2019; Herteliu et al., 2017; Baffy et al., 2020; Gammelgaard, 2016; Hughes, Stone, Aravopoulou, Tiu Wright, \& Machtynger, 2018; Ferreira \& Serpa, 2018a; Besançon, Rönnberg, Löwgren, Tennant, \& Cooper, 2019; Xu, 2018; Lemke, Mehrazar, Mazarakis, \& Peters, 2019; Wakeling et al., 2017.

In short, academic editors, in their activity, will have to be able to cope in a world of increasing open access dominance, with challenges, such as (i) journal indexing and metrics, measured through the 
number of citations per article (Tennant et al., 2019; Herteliu et al., 2017; Baffy et al., 2020; Gammelgaard, 2016); (ii) the increasing pressure for articles to explicitly indicate their "practitioner impact" (Hughes et al., 2018, p. 2); (iii) the growing preprint publication with manuscripts not previously peer-reviewed before being made publicly available (Ferreira \& Serpa, 2018a; Besançon et al., 2019; Tennant et al., 2019); (iv) the presence of references of articles in social networks assessed through Altmetrics or similar indicators (Xu, 2018; Lemke et al., 2019); (v) the mega-journals, which have a focus that covers a very large number of topics, such as, for example, humanities and/or social sciences (Wakeling et al., 2017); and, finally, (vi) decolonise the international scientific publication, acknowledging that scientific quality is not present only in the Anglophone centre's model and language (Banks et al., 2018; Trahar, Juntrasook, Burford, von Kotze, \& Wildemeersch, 2019).

Within this context, there may be a temptation to manipulate the ranking results through excessive and unnecessary citation of a given journal's own publications (Rovira, Codina, GuerreroSolé, \& Lopezosa, 2019; Herteliu et al., 2017), for example, through "coercive citation, review articles, editorials and letters, and online queuing (i.e., the number of articles pre-posted on the web)" (Wilhite, Fong, \& Wilhite, 2019, p. 1514).

Even in the above-mentioned situation, where challenges for the academic editor emerge that shape new situations, generating doubts and specific implications, there are values that are essential in the publication of scientific journals, in the respect for ethics standards in publications (Zernes, 2018), such as Honesty, Promptness, Competence, Dependability, Fairness, Accountability and Integrity (Table 2).

Table 2. Some values that are relevant to the publication of scientific journals

\begin{tabular}{l|l}
\hline Honesty & To act truthfully in all publishing related activities; be consistent with rules \\
\hline Promptness & To be punctual in meeting all responsibilities \\
\hline Competence & To accept roles only when capable by education and/or experience \\
\hline Dependability & To be trustworthy to fulfil obligations of the stakeholder position \\
\hline Fairness & To be free of bias in decision making \\
\hline Accountability & Answerable for all responsibilities \\
\hline Integrity & Adherence to all relevant practices common to journal publishing \\
\hline
\end{tabular}

Source: McCuen (2017, p. 2).

Perhaps the preprint publication may have increased relevance in scientific communication. According to Pagliaro (2019), "As we enter the third decade of the 21st century, the time has come for world's scholars to replace journal article 'submissions' with a free and open system widely based on freely accessible and freely reproducible preprints in which the value (i.e., quality) of scientific articles no longer needs peer review but is open to the evaluation and use of the whole scientific community which has all the tools and an obvious incentive to separate "wheat from chaff", identifying quality work for further valorization via subsequent utilization (and citation)" (p. 4).

The open peer review seems to us one of the paths to be developed towards a reformulation of the academic editor's role and can take on the role of the following (Table 3):

Table 3. Open peer review practices

\begin{tabular}{l|l}
\hline Practice & Description \\
\hline Transparent peer review & Authors and reviewers know each other's identities. \\
Open identities & $\begin{array}{l}\text { Reports are published together with the accepted manuscript. } \\
\text { Open reports }\end{array}$ \\
Rpen platforms & Review is not organized by the issuing journal, but by another organization. \\
\hline
\end{tabular}




\begin{tabular}{l|l}
\hline Practice & Description \\
\hline Dialogical peer review & $\begin{array}{l}\text { All members of the wider community can review an unpublished manuscript. } \\
\text { Open participation } \\
\text { Open interactions } \\
\text { promoted. } \\
\text { Original manuscripts are made available on preprint servers before the review } \\
\text { process begins. } \\
\text { Open commenting on the final manuscript is possible. }\end{array}$ \\
Open final-version commenting
\end{tabular}

Source: Dobusch \& Heimstädt, 2019, p. 613. Adapted from Ross-Hellauer (2017).

This is a situation for which there is no easy or unique solution. However, we consider that advertising the identity of the evaluators while the gatekeepers of the legitimacy of scientific publications is an inevitable path to take in order to increase the quality control of the scientific publication (Dobusch \& Heimstädt, 2019) and, at the same time, legitimizing the position of the academic editor (Ferreira \& Serpa, 2018b).

\section{Conclusion}

This paper aims to add to the discussion of the (re)formulation of the academic editor's role, considering that this character, in the myriad of changes that the academic and scientific arena are going through, is, and will remain, the ultimate guardian of the scientific quality of what is published and, hence, public.

Even though it is acknowledged that financial interests are present in scientific publishing (Baffy et al., 2020), autonomy in editorial decisions, which can be improved, is a feature and a vital element of integrity in scientific publishing.

\section{References}

Abbott, A. (2019). Career stage and publication in American academia. Sociologia, Problemas e Práticas, 90, 9-30. doi: 10.7458/spp20199014297.

Baffy, G., Burns, M. M., Hoffmann, B., Ramani, S., Sabharwal, S., Borus, J. F., ... Ingelfinger, \& J. R. (2020). Scientific authors in a changing world of scholarly communication: What does the future hold? The American Journal of Medicine, 133(1), 26-31. doi: 10.1016/j.amjmed.2019.07.028.

Banks, G. C., Field, J. G., Oswald, F. L., O’Boyle, E. H., Landis, R. S., Rupp, D. E., \& Rogelberg, S. G. (2018). Answers to 18 questions about open science practices. Journal of Business and Psychology, 34(3), 257-270. doi: 10.1007/s10869-018-9547-8.

Besançon, L., Rönnberg, N., Löwgren, J., Tennant, J., \& Cooper, M. (2019). Open up: A survey on open and nonanonymized peer reviewing. Preprints, 2019050098. doi: 10.20944/preprints201905.0098.v2.

Chiriboga, L. (2019). The changing landscape of scientific publishing. Journal of Histotechnology, 42(3), 95-97. doi: 10.1080/01478885.2019.1636554.

Dobusch, L., \& Heimstädt, M. (2019). Predatory publishing in management research: A call for open peer review. Management Learning, 50(5), 607-619. doi:10.1177/1350507619878820

Ferreira, C. M., \& Serpa, S. (2018a). The importance of preprint in scientific publication: Perspectives and challenges. The Journal of Social Sciences Research, 4(12), 642-647. doi: 10.32861/jssr.412.642.647.

Ferreira, C. M., \& Serpa, S. (2018b). Publicising the Identified Peer-Reviewer: Legitimacy and Quality of the Scientific Publication. The International Journal of Interdisciplinary Educational Studies, 13(1), $11-17$. doi:10.18848/2327-011x/cgp/v13io1/11-17

Gammelgaard, J. (2016). Citation and the hidden authority. International Journal of Social Science Studies, 4(12). doi: 10.11114/ijsss.v4i12.1956,

Ghanbari Baghestan, A., Khaniki, H., Kalantari, A., Akhtari-Zavare, M., Farahmand, E., Tamam, E., ..., \& Danaee, M. (2019). A crisis in "open access": Should communication scholarly outputs take 77 years to become open ccess? SAGE Open, 9(3), 1-8. doi: 10.1177/2158244019871044. 
Herteliu, C., Ausloos, M., Ileanu, B., Rotundo, G., \& Andrei, T. (2017). Quantitative and qualitative analysis of editor behavior through potentially coercive citations. Publications, 5(2), 15, 1-16. doi: 10.3390/publications5020015.

Hughes, T., Stone, M., Aravopoulou, E., Tiu Wright, L., \& Machtynger, L. (2018). Academic research into marketing: Many publications, but little impact? Cogent Business $\mathcal{E}$ Management, 5(1). doi: 10.1080/23311975.2018.1516108.

Kortabarria, L. (2019). A new model for scientific publications: The case for $100 \%$ free open access journals and why they can succeed. SocArxiv Papers, Preprints. doi: 10.31235/osf.io/25rwu.

Lemke, S., Mehrazar, M., Mazarakis, A., \& Peters, I. (2019). "When you use social media you are not working": Barriers for the use of metrics in social sciences. Frontiers in Research Metrics and Analytics, 3. doi: 10.3389/frma.2018.00039.

McCuen, R. (2017). Advancing scientific knowledge: Ethical issues in the journal publication process. Publications, 6(1), 1. doi: 10.3390/publications6010001.

Miguel, S., Tannuri de Oliveira, E., \& Cabrini Grácio, M. (2016). Scientific production on open access: A worldwide bibliometric analysis in the academic and scientific context. Publications, 4(1), 1. doi: 10.3390/publications4010001.

Nygaard, L. P. (2017) Publishing and perishing: An academic literacies framework for investigating research productivity, Studies in Higher Education, 42(3), 519-532. doi: 10.1080/03075079.2015.1058351.

Omer, R. A. (2015). International scientific publication in ISI journals: Chances and obstacles. World Journal of Education, 5(6). doi: 10.5430/wje.v5n6p81.

Pagliaro, M. (2019). Scientific publishing: Education as the key enabler for the transition to open science. Preprints. doi: 10.20944/preprints201910.0057.v1.

Primack, R. B., Regan, T. J., Devictor, V., Zipf, L., Godet, L., Loyola, R., ..., \& Koh, L. P. (2019). Are scientific editors reliable gatekeepers of the publication process? Biological Conservation, 238, 1-5, 108232. doi: 10.1016/j.biocon.2019.108232.

Rovira, C., Codina, L., Guerrero-Solé, F., \& Lopezosa, C. (2019). Ranking by relevance and citation counts, a comparative study: Google Scholar, Microsoft Academic, WoS and Scopus. Future Internet, 11(9), 202. doi: 10.3390/fi11090202.

Tennant, J. P., Crane, H., Crick, T., Davila, J., Enkhbayar, A., Havemann, J., ..., \& Vanholsbeeck, M. (2019). Ten hot topics around scholarly publishing. Publications, 7(2), 34. doi: 10.3390/publications7020034.

Tenopir, C., Dalton, E., Fish, A., Christian, L., Jones, M., \& Smith, M. (2016). What motivates authors of scholarly articles? The importance of journal attributes and potential audience on publication choice. Publications, 4(3), 22. doi: 10.3390/publications4030022.

Trahar, S., Juntrasook, A., Burford, J., von Kotze, A., \& Wildemeersch, D. (2019). Hovering on the periphery? "Decolonising" writing for academic journals. Compare: A Journal of Comparative and International Education, 49(1), 149-167. doi: 10.1080/03057925.2018.1545817.

Trapp, J. (2019). Predatory publishing, hijacking of legitimate journals and impersonation of researchers via special issue announcements: A warning for editors and authors about a new scam. Australasian Physical $\mathcal{E}$ Engineering Sciences in Medicine, 1-2. doi: 10.1007/s13246-019-00835-5.

$\mathrm{Xu}, \mathrm{S}$. (2018). Issues in the interpretation of "altmetrics" digital traces: A review. Frontiers in Research Metrics and Analytics, 3. doi: 10.3389/frma.2018.00029.

Wakeling, S., Willett, P., Creaser, C., Fry, J., Pinfield, S., \& Spezi, V. (2017). Transitioning from a conventional to a "mega" journal: A bibliometric case study of the journal medicine. Publications, 5(2), 7 . doi: 10.3390/publications5020007.

Watson, R., \& Xue, C. (2019). Things not to ask an editor. Journal of Advanced Nursing, 75(11), 2270-2271. doi: $10.1111 /$ jan.14158.

Wilhite, A., Fong, E. A., \& Wilhite, S. (2019). The influence of editorial decisions and the academic network on self-citations and journal impact factors. Research Policy, 48(6), 1513-1522. doi: 10.1016/j.respol.2019.03.003.

Wong, C.-Y. (2019). A century of scientific publication: Towards a theorization of growth behavior and researchorientation. Scientometrics, 119(1), 357-377. doi: 10.1007/s11192-019-03048-5.

Zernes, S. (2018). Two levels of ethical issues in academic publishing. Science and Engineering Ethics, 25(5), 16031604. doi: 10.1007/s11948-018-0035-3. 